\title{
Dynamic Compressive Behavior of Ice Material
}

\author{
Chuanxiong Liu
}

School of Civil Engineering and Architecture, Huaiyin Institute of Technology, Huai'an 223001, china

Email:liu_cx88@sina.com

Keywords: Ice, Strain-rate effect, Dynamic strength, Temperature

Abstract. In order to invesigate the dynamic behavior of ice in compressive loading, tests on ice specimens at $-10^{0} \mathrm{C} \sim-25^{0} \mathrm{C}$ were conducted by using the SHPB apparatus in the strain rate range from 500/s to 2000/s. Strain-rate effects and the influence of freezing preserve time were studied. . Experimental results show that the dynamic compressive strength of ice has an effect of strain-rate enhancement and the freezing preserve time has no influence to its dynamic compressive strength., and the compressive strength decreases with the increasing of temperature.

\section{Introduction}

Aircrafts and buildings, especially its ornamental structure such as glass curtain wall, shall be suffered inevitably from the impact by hailstone in some certain situations. As a result, these structures may partly failed, or occur cracks inside and become a hidden danger. Thus, it is necessary to understand the failure mode and its mechanism of the impact of hailstone on such structures. However, there is some lack of knowledge about the dynamic behavior of ice because of the difficulty of testing techniques for materials like ice. As well known, the experimental result for ice under dynamic loading mainly varies with different methods of crystal, loading conditions and temperatures. For example, K.Him et al.[1] put forward that the dynamic compressive strength for ice had a same value of 19.7 MPa at strain-rates 400 2600s ${ }^{-1}$, in contrast, M. Shazly et al.[2] believe that the dynamic compressive strength for ice increased with strain-rates at 60 1400s ${ }^{-1}$. It should be noticed that the magnitude of peek strain corresponding to the failure stress for these quasi-brittle materials like ice was just about $10^{-3}$. Therefore, it is important to ensure a constant strain-rate loading condition in testing so as to avoid the specimen failing before stress getting uniformity. But previous studies have failed to consider the loading conditions.

The purpose of this work is to investigate the effect of strain-rate and exposed temperature on the compressive strength of ice experimentally.

Method of crystal of ice. Cylindrical specimens with a diameter of $15 \mathrm{~mm}$ and a length of $5 \mathrm{~mm}$ were used in tests. The apparatus employed for freezing common mineral water used in test is shown in Fig.1. This idea originates in article [2]. Firstly, fanning the adhesive tape in the flute of the mould, then putting the two short cylindrical body on the adhesive tape either end, next enwrapping these two short cylindrical body with adhesive tape, Finally, infusing water into the inter-space between these two enwrapped short cylindrical body. The details can see about [2].

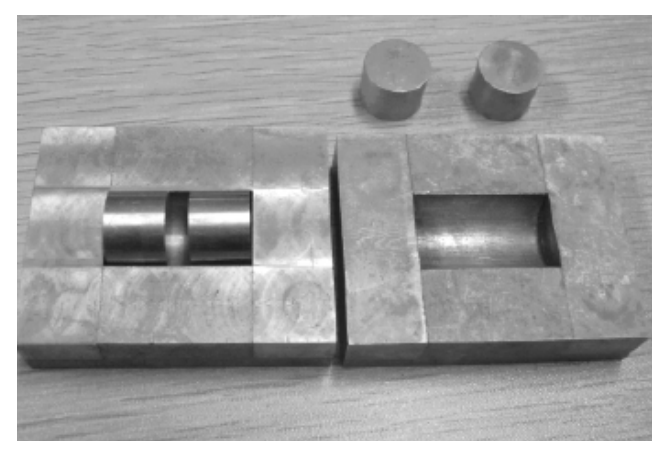

Fig.1 Mould for freezing ice specimens 
Experimental temperature. The sample mould was putted into a thermostat container for freezing, and had been maintained for $1 \mathrm{~h}$ to ensure final thermal steady state in specimens at target temperature of $-10^{\circ} \mathrm{C}$ and $25^{\circ} \mathrm{C}$.

Loading condition. In recent years, the SHPB(Split Hopkinson Pressure Bar) apparatus has become a commonly set up to determine the dynamic compressive behavior of materials. In the present experiments, a set of SHPB apparatus, the incident bar and transmitted bar have a same diameter of $20 \mathrm{~mm}$, and have lengths of $4 \mathrm{~m}$ and $3 \mathrm{~m}$ respective; was used for testing the dynamic compressive behavior of ice. A schematic illustration of the SHPB apparatus is shown in Fig.2.

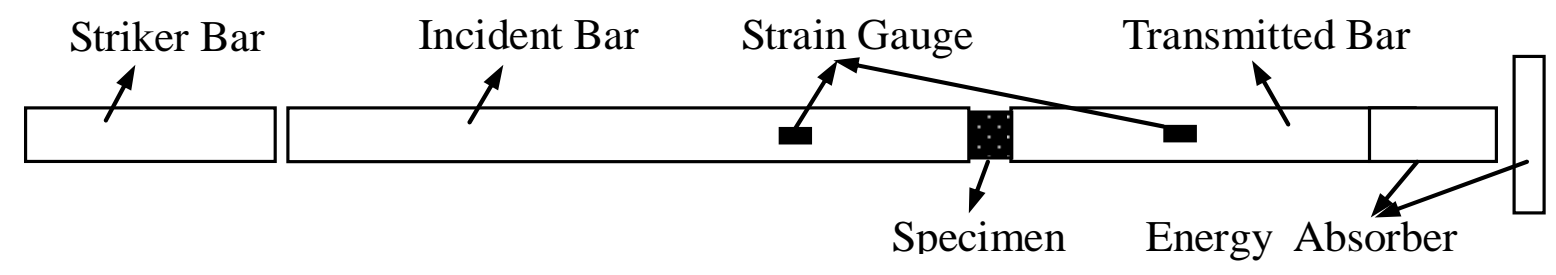

Fig.2 A schematic illustration of the SHPB apparatus

Results and discussion. The stress-strain curves obtained form dynamic compressive loading tests on ice at $-10^{\circ} \mathrm{C}$ and $-25^{\circ} \mathrm{C}$ were shown in Fig.3 and Fig.4, respectively. it was obviously that both strain-rate and temperature have seriously effect on the dynamic compressiv behavior of ice. On the one hand, at the same temperature of $-10^{\circ} \mathrm{C}$ or $-25^{\circ} \mathrm{C}$, the peek stress of ice increase with the increasing of strain-rates, and the strain in responding to the peek stress also raise with the enlargement of strain-rates, which is agreement with [2] [4]. On the other hand, at the same strain-rate, the dynamic compressive strength of ice at temperature of $-25^{\circ} \mathrm{C}$ evidently exceed that of ice at temperature of $-10^{\circ} \mathrm{C}$, which indicated that the lower the temoerature of ice is, the higher the dynamic compressive strength of ice will be. But, it seemed that there was tiny difference between the strain in responding to the peek stress under these two temperatures.

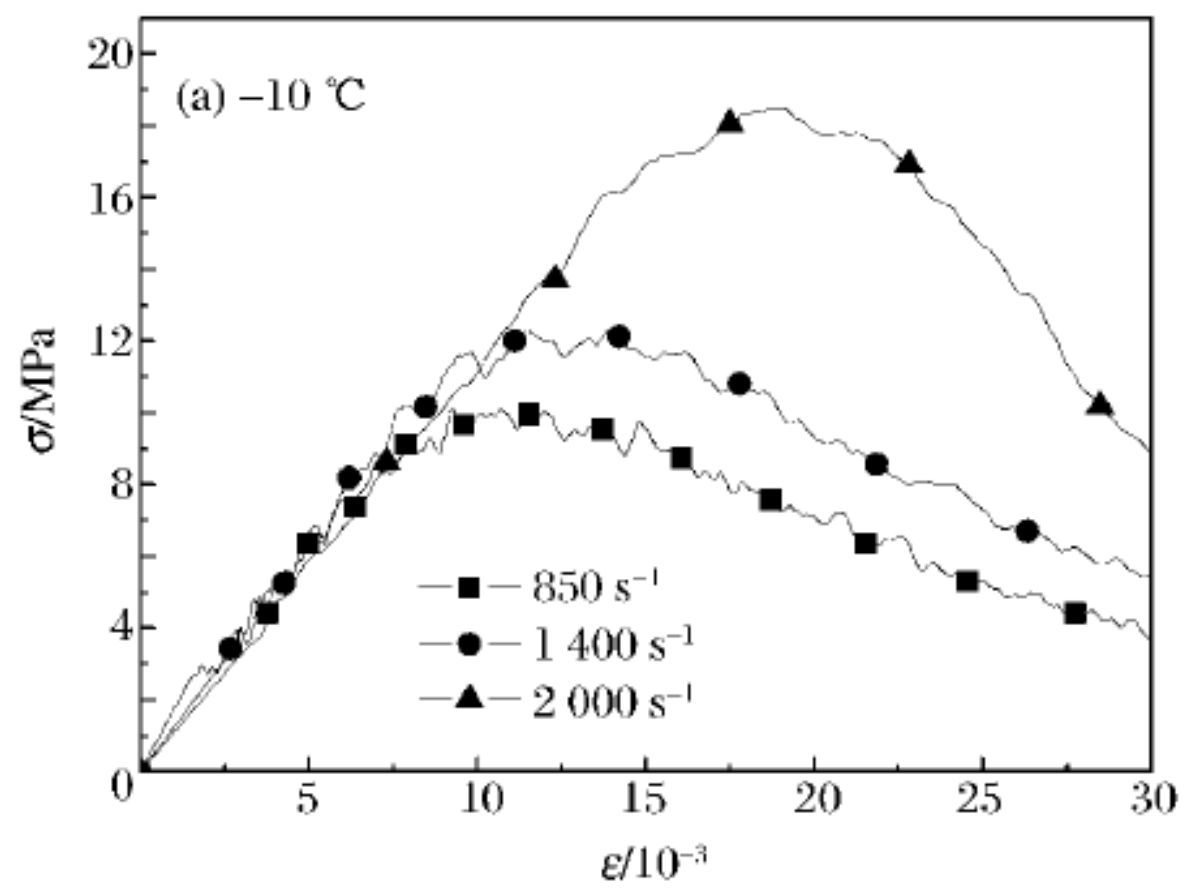

Fig.3 Stress-strain curves of ice at $-10^{0} \mathrm{C}$ 


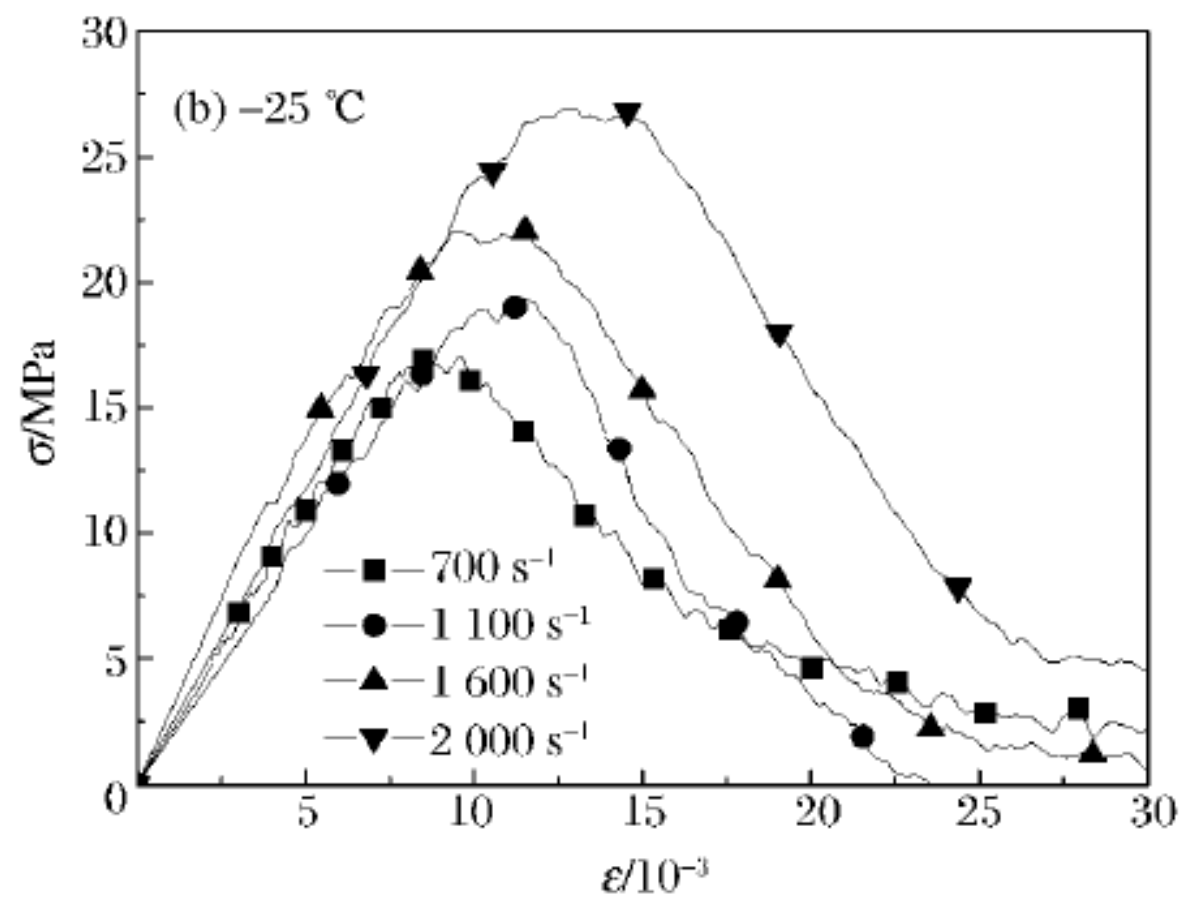

Fig. 4 Stress-strain curves of ice at $-25^{\circ} \mathrm{C}$

The strain-rate and temperrature effect on the dynamic compressive strength of ice may be mainly duo to the interior friction resistance of ice. The development of inner crack of ice under dynamic loading could be hindered to a great extent by the slide friction resistance of ice, and the higher strain-rate is or the lower temperature is, the larger the slide friction resistance of ice will be. Therefore, the dynamic compressive strength of ice increases with the increasing of strain-rate, and also enhances with decrease temperature.

Fig.5 shows the stress-strain curves of ice specimens at different freezing preserve time and strain-rates. It is clearly that the freezing preserve time of ice specimen has no influence to its dynamic compressive strength., which indicats the inner micro structure of ice are in steady state after freezing for $1.5 \mathrm{~h}$.

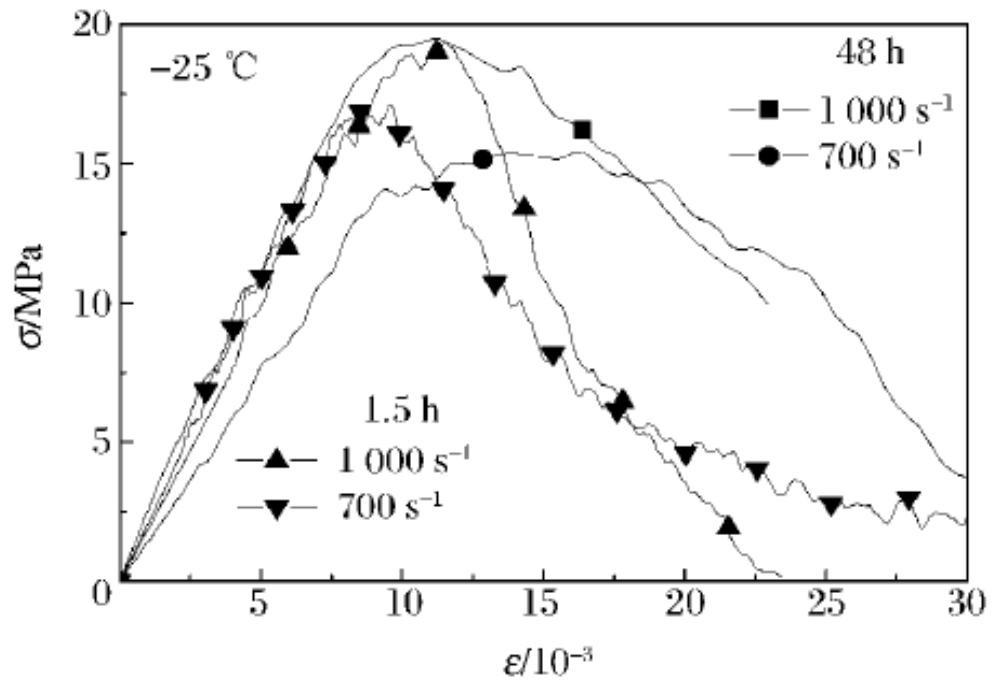

Fig.5 stress-strain curves of ice specimens at different freezing preserve time and strain-rates 


\section{Conclusions}

Based on the researches cited above the main conclusions are summarized as follows:

1) The peek stress and its responding strain of ice incerase with the increasing of strain-rate;

2) The dynamic compressive strength of ice enhance with decrease temperature, but the temperrature seems no influence to the strain in responding to the peek stress.

3) The freezing preserve time of ice specimen has no influence to its dynamic compressive strength.

\section{References}

[1] Kim. H, Keune J N. Compressive strength of ice at impact strain rates [J]. Material Science. 2007,42(8):2802-2806.

[2] Shazly M, Prakash V, Lerch B A. High strain rate behavior of ice under uniaxial compression [J]. International journal of solids and structures. 2009, 46(6):1499-1515.

[3]Lili Wang, Yonggang Wang. The important role of stress waves in the study on dynamic constitutive behavior of materials by SHPB [j]. Explosion and Shock Waves. 2005, 25(1):17-25.

[4]Dutta P K, Cole D M, Schulson E M, et al. A fracture study of ice under high strain rate loading [J].International journal of Offshore Polar Engineering. 2004, 14(13):465-472. 